\title{
Hyperventilation-Induced Cerebrovascular Reactivity among Hypertensive and Healthy Adolescents
}

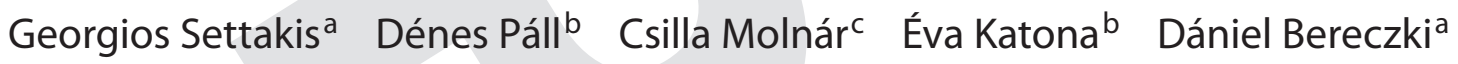 \\ Béla Fülesdic
}

${ }^{a}$ Department of Neurology, ${ }^{b}$ First Department of Medicine, and ${ }^{\mathrm{C}}$ Anesthesiology and Intensive Care, University of Debrecen, Health and Medical Science Center, Debrecen, Hungary

\section{Key Words}

Arterial hypertension - Adolescence · Transcranial Doppler sonography $\cdot$ Cerebrovascular reactivity

\begin{abstract}
Background: It is known that cerebral vasoreactivity is altered in adult arterial hypertension but no information is available about cerebral arteriolar function in hypertensive adolescents. Therefore, the aim of the present work was to assess cerebral vasoreactivity responses in adolescent hypertension. Methods: 113 hypertensive and 58 normotensive adolescents were assessed with transcranial Doppler sonography by using voluntary hyperventilation (HV) as vasoconstrictory stimulus. Absolute blood flow velocities (systolic, mean and diastolic) and pulsatility indices (PIs) at rest and after HV, as well as percentage change of the blood flow velocities after HV were compared among the groups. Results: Blood flow velocities at rest were significantly higher in hypertensive individuals, while PIs were similar in the two groups. After HV, all blood flow velocity parameters were higher among hypertensive teenagers than in healthy controls, while Pls did not differ between the two groups. Taking the relative changes after HV into account, it was found that $\mathrm{HV}$ induced a more pronounced change of the systolic and mean blood flow velocities of the control sub-
\end{abstract}

\footnotetext{
KARGER

Fax +41613061234

E-Mail karger@karger.ch

www.karger.com

(C) 2006 S. Karger AG, Basel

1420-4096/06/0000-0000\$23.50/0

Accessible online at:

www.karger.com/kbr
}

jects than in hypertensive adolescents. Conclusions: Cerebrovascular reactivity to hypocapnia is decreased in hypertensive adolescents as compared to healthy teenagers. Further studies are needed to clarify the clinical significance of altered cerebral microvascular function in adolescent hypertension.

Copyright $\odot 2006$ S. Karger AG, Basel

\section{Introduction}

Hypertension is one of the most important risk factors for cerebral angiopathies. Both macro- and microvascular functions may be affected. Macrovascular changes include increased intima-media thickness, stenoses and occlusions of the large cerebral arteries [1,2]. It is also widely accepted that chronically increased blood pressure induces alterations in the cerebral arteriolar tone and shifts the cerebral autoregulatory curve toward higher blood pressure values [3]. Due to this mechanism, the brain arteriolar tone chronically increases in order to keep the cerebral blood flow constant. As a consequence of this increased arteriolar tone, a decreased reactivity against vasodilatory and vasoconstrictory stimuli may be present. This decreased arteriolar reactivity can be demonstrated by measuring cerebral hemodynamics under

Béla Fülesdi, MD

Department of Anesthesiology and IC, University of Debrecen

Nagyerdei krt. 98

HU-4012 Debrecen (Hungary)

Tel./Fax +36 52413 434, E-Mail fulesdi@jaguar.dote.hu 
administration of different vasoactive stimuli, such as intravenous acetazolamide [4], $\mathrm{CO}_{2}$ inhalation [5] and decreasing systemic blood pressure [6].

Previous vasoreactivity tests exclusively reported on adult hypertensive patients and no information is available so far about cerebral hemodynamics assessed in adolescent hypertension. Although adolescent hypertension is not very frequent (the prevalence varies from 0.4 to $12 \%$ in epidemiological studies [7-10]), it may predict hypertension and increased cardiovascular risk during adulthood [11-15]. As altered cerebral vasoreactivity normalizes some months after initiation of an effective antihypertensive treatment [16], the importance of diagnosing altered cerebral microvascular function in adolescent hypertensive patients is of high importance. It is believed that early diagnosis and proper treatment decreases the incidence of secondary organ damage caused by hypertension. For assessing cerebral hemodynamics in adolescents, we included patients and control subjects from the population-based cohort of the Debrecen Hypertension Study [17] in order to answer the following two questions: Can we detect differences between cerebral blood flow velocities of healthy and hypertensive adolescents? Is there any difference between cerebral vasoreactivity of healthy and hypertensive teenagers as measured during hyperventilation tests?

\section{Subjects and Methods}

Healthy and hypertensive adolescents were asked to participate in the present study. This was a part of a population-based screening program which aimed to assess the prevalence and the influencing factors of adolescent hypertension in Debrecen, a city of 230,000 inhabitants [17]. At baseline investigations, 10,359 subjects underwent three consecutive blood pressure measurements (Omron M4 digital oscillometry manometer; Omron, Healthcare $\mathrm{GmbH}$, Hamburg, Germany). The three systolic and diastolic blood pressure values were averaged. Based on age, gender and height, 32 subgroups of subjects were formed in order to draw the 90 th percentile values of the blood pressure measurements. Those adolescents whose blood pressure was above the limit of the 90th percentile underwent an additional $2 \times 3$ blood pressure measurement with an interval of 3 months each. Originally, 1,641 teenagers were found to have blood pressure values greater than the 90th percentile, among them 1,461 decided to participate in the further investigations. In these 1,461 adolescents the nine casual blood pressure values were averaged and compared with the 95th percentile BP values of the original population $(n=10,359)$. Finally, arterial hypertension was proven in 216 adolescents. 113 of the 216 hypertensive teenagers and 58 from the healthy control group decided to participate in the present study.

Transcranial Doppler measurements: The middle cerebral artery was insonated at $50 \mathrm{~mm}$ depth through the temporal window on both sides. Systolic, mean, diastolic blood flow velocities and pulsatility indices were recorded. Measurements were performed both at rest and after $60 \mathrm{~s}$ of voluntary hyperventilation (HV). Subjects were asked to perform serial deep inspirations with a frequency of approximately $25-28 / \mathrm{min}$ on average. The second transcranial Doppler measurement was performed exactly $60 \mathrm{~s}$ after starting the HV procedure. All measurements were performed by the same investigator (G.S.), who was unaware of the patients' condition (hypertensive or not).

Statistical analysis: Means and standard deviations were calculated for all values. For statistical evaluation both absolute values of the different parameters and the percent changes after $\mathrm{HV}$ were taken into account. The percent changes were calculated based on the following formula:

$$
\% \text { change }=100 \times\left(\mathrm{MCA}_{\text {test }}-\mathrm{MCA}_{\text {rest }}\right) / \mathrm{MCA} \text { rest. }
$$

The statistical distribution of the data was evaluated by the Shapiro-Wilk test. If this showed a non-normal distribution, Kruskall-Wallis test was used for further analysis. Parameters with normal distribution were compared by t tests. A p $<0.05$ value was decided to indicate statistically significant differences.

\section{Results}

The most important characteristics of the hypertensive and control groups are summarized in table 1. 55 female and 58 male hypertensive teenagers were studied. The control group consisted of 29 females and 29 males. The difference between the numbers of hypertensive and non-hypertensive subjects can be explained by the different willingness of the teenagers in being subjected for further investigations. The age of the hypertensive individuals was somewhat higher than that of the control group, corresponding on average to a 6-month difference. There were no differences in height. Body mass index was significantly higher among hypertensive teenagers than in control subjects. Although serum glucose, creatinine, total and LDL cholesterol levels were higher in the hypertensive group, all these parameters were within the normal limit.

Transcranial Doppler measurements: Middle cerebral artery blood flow velocities in the resting state are depicted in figure 1. Mean and diastolic blood flow velocities were significantly different in the hypertensive and in the normotensive control group. In contrast, systolic blood flow velocities (hypertensive: $112.5 \pm 29.5$, control: 109.6 $\pm 23.0 \mathrm{~cm} / \mathrm{s}, \mathrm{p}=0.47$ ) and pulsatility indices (hypertensive: $1.06 \pm 0.26$, control: $1.09 \pm 0.19, \mathrm{p}=0.36$ ) were similar among adolescents suffering from hypertension and in controls. Transcranial Doppler sonography parameters after $60 \mathrm{~s}$ of $\mathrm{HV}$ are depicted in figure 2. After hyperventilating, all the three blood flow velocity parameters were higher among hypertensive teenagers than the 


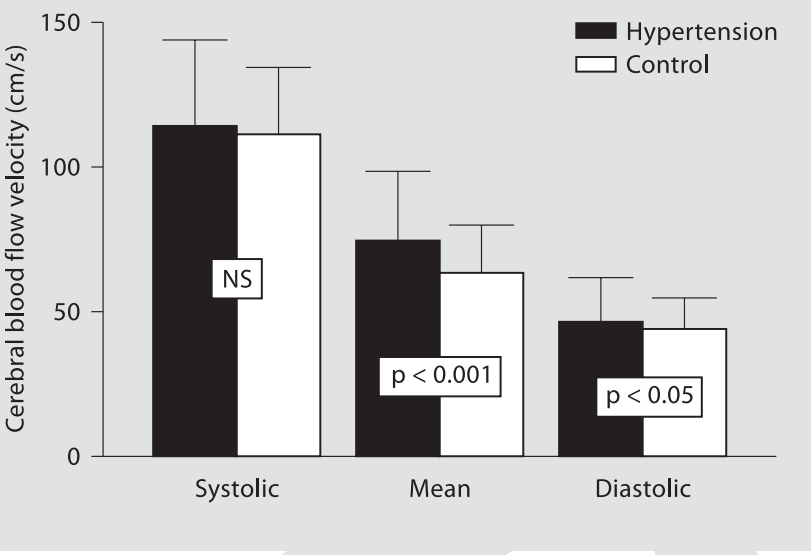

Fig. 1. Blood flow velocities in hypertensive and healthy adolescents at rest.

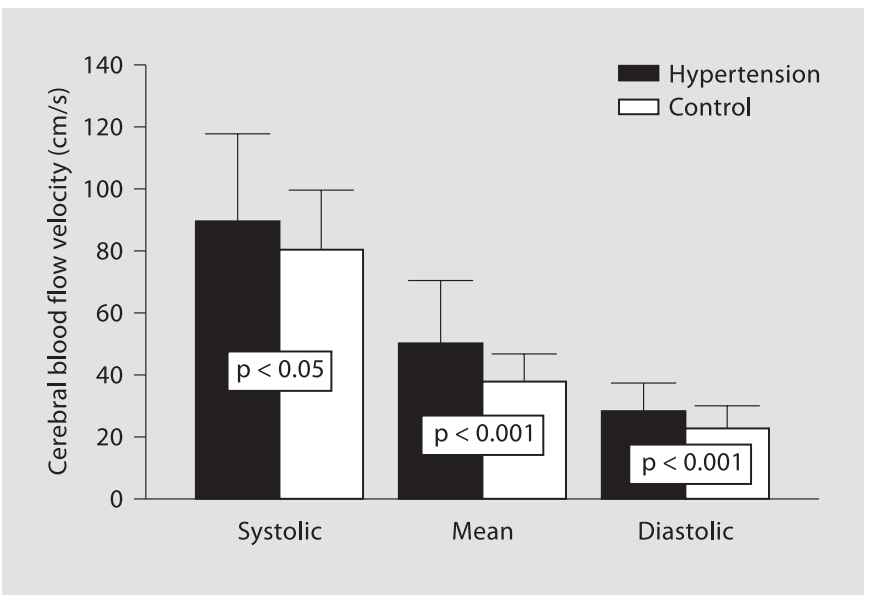

Fig. 2. Blood flow velocities in hypertensive and healthy adolescents at $60 \mathrm{~s}$ of voluntary HV.
Table 1. Characteristics and laboratory results of the investigated adolescents (values are mean \pm SD)

\begin{tabular}{lccl}
\hline & Hypertensive & Control & Significance \\
\hline Female/male & $55 / 58$ & $29 / 29$ & $\mathrm{NS}$ \\
Age, years & $16.4 \pm 1.1$ & $15.8 \pm 0.7$ & $\mathrm{p}<0.001$ \\
$\mathrm{BMI}, \mathrm{kg} / \mathrm{m}^{2}$ & $22.8 \pm 4.1$ & $20.2 \pm 2.6$ & $\mathrm{p}<0.001$ \\
Glucose, mmol/l & $5.5 \pm 1.3$ & $4.7 \pm 1.1$ & $\mathrm{p}<0.001$ \\
Carbamide nitrogen, $\mathrm{mmol} / \mathrm{l}$ & $4.7 \pm 1.1$ & $4.4 \pm 1.1$ & $\mathrm{NS}$ \\
Creatinine, $\mu \mathrm{mol} / \mathrm{l}$ & $86.6 \pm 13.6$ & $72.5 \pm 9.7$ & $\mathrm{p}<0.001$ \\
Triglyceride, $\mathrm{mmol} / \mathrm{l}$ & $1.0 \pm 0.6$ & $0.9 \pm 0.7$ & $\mathrm{NS}$ \\
Cholesterol, $\mathrm{mmol} / \mathrm{l}$ & $4.3 \pm 0.8$ & $3.9 \pm 0.6$ & $\mathrm{p}<0.01$ \\
HDL cholesterol, $\mathrm{mmol} / \mathrm{l}$ & $1.4 \pm 0.3$ & $1.8 \pm 2.7$ & $\mathrm{NS}$ \\
LDL cholesterol, mmol/l & $2.3 \pm 0.7$ & $2.1 \pm 0.5$ & $\mathrm{p}<0.01$ \\
\hline
\end{tabular}

Table 2. Percent changes of the transcranial Doppler parameters after $60 \mathrm{~s}$ hyperventilation as compared with the resting value (values are means $\pm \mathrm{SD}$ )

\begin{tabular}{lllr}
\hline & $\begin{array}{l}\text { Hypertensive } \\
(\mathrm{n}=113)\end{array}$ & $\begin{array}{l}\text { Control } \\
(\mathrm{n}=58)\end{array}$ & p value \\
\hline Systolic & $21.0 \pm 19.0$ & $25.9 \pm 12.5$ & $<0.05$ \\
Mean & $32.3 \pm 14.7$ & $35.6 \pm 15.8$ & 0.18 \\
Diastolic & $40.4 \pm 18.1$ & $45.5 \pm 15.2$ & $<0.05$ \\
PI & $54.8 \pm 54.2$ & $47.1 \pm 30.4$ & 0.27 \\
\hline
\end{tabular}

healthy controls, while pulsatility indices did not differ between the two groups (hypertensive: $1.59 \pm 0.53$, control: $1.58 \pm 0.35, \mathrm{p}=0.95)$. The percent changes of the different transcranial Doppler parameters after HV are

Cerebrovascular Reactivity in Adolescent Hypertension summarized in table 2. Taking the relative changes after $\mathrm{HV}$ into account, it was found that $\mathrm{HV}$ induced a more pronounced change of the systolic and diastolic blood flow velocities of the control subjects than in hypertensive adolescents. No significant difference was found between relative changes in mean blood flow velocities and pulsatility indices of the hypertensive and control group.

\section{Discussion}

In our study we demonstrated higher baseline blood flow velocities among hypertensive adolescents as compared to those of healthy teenagers. A further observation of the present report is that vasoconstrictory ability of the cerebral arterioles is decreased in hypertension, indicating cerebral arteriolar dysfunction. 
The absolute blood flow velocities in the present study were different among healthy and hypertensive individuals both at rest and after HV. Although this was true for all velocities (i.e. systolic, mean and diastolic velocities), the most important parameter to take into account is mean blood flow velocity, because transcranial Doppler sonography does not measure cerebral blood flow, only changes in mean cerebral blood flow velocities are proportional to blood flow changes in the corresponding vascular territory. Therefore, in the further discussion we focus mainly on mean blood flow velocity values.

Previous cerebral blood flow measurements were mainly performed on adult, middle-aged hypertensive and normotensive individuals and little information is available about cerebral hemodynamics in adolescence. The middle cerebral artery blood flow velocities measured in the present study correspond to those observed among healthy adolescents by Brouwers et al. [18]. Many previous studies stated that cerebral blood flow and cerebral blood flow velocities are similar in hypertensive and normotensive adults $[3,19,20]$. Other investigators reported higher cerebral blood flow velocities among hypertensives as compared to healthy individuals $[4,21,22]$ and our results are in accordance with these results. To explain the discrepancies between the two sets of observations, we have to note that the study populations were generally different: those who observed similar blood flow velocities among hypertensive and normotensive individuals mainly included middle-aged patients [3, 19, 20], while in the other group of reports younger patients were assessed $[4,21,22]$. It is known that resting cerebral blood flow velocity shows a decreasing tendency over age. Therefore, it is conceivable that aging mimics and equalizes the slight differences, which are present in younger age. This is also supported by the observations of Lipsitz et al. [5] who found that resting blood flow velocities were higher in younger subjects than those observed in normotensive or hypertensive elderly patients and velocities measured in the latter two groups were equal.

$\mathrm{HV}$ induces reduction in arterial $\mathrm{CO}_{2}$ partial pressure. Hypocapnia results in vasoconstriction of the cerebral arterioles and therefore cerebrovascular resistance increases. Transcranial Doppler sonography enables the non-invasive detection of the blood flow velocities within the large cerebral arteries forming the circle of Willis. After an increase in cerebrovascular resistance evoked by $\mathrm{HV}$, a decrease of the blood flow velocities in the large vessels will occur $[18,23,24]$. It has been demonstrated that the diameter of the large cerebral arteries remains stable during the vasoreactivity maneuver $[25,26]$. There- fore, changes in blood flow velocities measured by transcranial Doppler sonography during hypocapnia reflect the increase of the vascular tone at the level of the cerebral arterioles and are proportional to changes of cerebral blood flow in the territory of the assessed artery. A good short- and long-term reproducibility of the HV-induced cerebral vasoreactivity responses was demonstrated previously [27] and the method has been used in different conditions for assessing cerebrovascular reactivity [2830].

Decreased cerebral vasoreactivity among hypertensive patients as compared to healthy volunteers has been already observed in several studies $[4,5,19,29,31]$. The majority of these previous studies assessed vasoreactivity during hypercapnic stimuli, such as $\mathrm{CO}_{2}$ inhalation [5], intravenous acetazolamide [4], physical exercise [19] and breath-holding [31]. HV test, assessing the effect of hypocapnia on cerebral hemodynamics, was performed only in two studies of hypertension [28, 29]. In their small study, Malatino et al. [29] compared cerebral vasoreactivity in hypertensive and healthy adults during HV. They found that cerebral vasoreactivity was of similar extent in hypertensive and normotensive individuals and the only finding was that blood flow velocities normalized faster in the hypertensive group after stopping HV. A similar observation has been described by Zatik et al. [28] in preeclamptic pregnant women.

The pathophysiological background of these altered cerebral vasoreactivity responses is related to the mechanism of cerebral autoregulation. The main goal of this mechanism is to maintain a constant cerebral blood flow during alterations of the cerebral perfusion pressure. As cerebral perfusion pressure is proportional to the mean arterial blood pressure, an increase in mean arterial pressure results in an increase in the cerebral perfusion pressure. Until a certain limit, cerebral autoregulation compensates the increase in cerebral perfusion pressure by increasing the cerebrovascular resistance. The main actors of this mechanism are cerebral arterioles. Different factors, e.g. mechanical, metabolic, vasoactive substances, may play a role, resulting finally in an increase of the cerebrovascular resistance by constricting the cerebral arterioles [32]. In chronic hypertension, the resistance vessels adapt to elevated cerebral perfusion pressure, by increasing the wall/lumen ratio, which impairs the ability of the vessels to dilate or to constrict after different stimuli $[33,34]$. Our results can be explained by this mechanism: a constrictory stimulus, such as HV, is presumably not able to induce further vasoconstriction in already constricted arterioles of the hypertensive patients 
to a similar extent as among normotensive individuals. Similar to this, vasodilatory stimuli may cause also a less intensive vasodilation in the constricted arterioles, which may explain the impairment of vasodilatory responses among hypertensive patients.

There are data indicating that impaired cerebrovascular reactivity is a risk factor for ischemic stroke in hypertensive asymptomatic individuals [35]. The main limitation of the cerebral vasoreactivity studies performed among hypertensive patients is that although they detected altered cerebral arteriolar function, follow-up observations were not implicated. Therefore all these studies, including the present one, can be considered as pathophysiological descriptions of the actual hemodynamic status in hypertension.

Finally, we have to mention the limitation of the present study. During the HV tests no capnography was ap- plied. In a previous study we proved that $\mathrm{pCO}_{2}$ in capillary blood does not change significantly during the breath-holding test, whereas $\mathrm{pCO}_{2}$ significantly decreases after HV (arterial samples were not drawn as it was considered to be unethical in healthy volunteers) [36]. Previous studies reported on satisfactory reproducibility of both methods and a good agreement with other vasodilatory testing using different stimuli $[37,38]$.

We conclude that cerebrovascular reactivity in hypertensive adolescents is decreased as compared to healthy teenagers. This refers to an altered cerebral arteriolar function, which can be detected already in the very early, from a cardio- and cerebrovascular point of view, asymptomatic phase of hypertension. The present study serves mainly pathophysiological results; the clinical significance of the findings has to be clarified in further studies.

\section{References}

1 Lemne C, Jogestrand T, de Faire U: Carotid intima-media thickness and plaque in borderline hypertension. Stroke 1995;26:34-39.

2 Pauletto P, Palatini P, DaRos S, Pagliara V, Santipolo N, Baccilieri S, Casiglia E, Mormino P, Pessina AC: Factors underlying the increase in carotid intima-media thickness in borderlinehypertensives. Arterioscl Thromb Vasc Biol 1999;19:1231-1237.

3 Strandgaard S, Olesen J, Skinhoj E, Lassen NA: Autoregulation of brain circulation in severe arterial hypertension. Br Med J 1973;i:507-510.

4 Ficzere A, Valikovics A, Fülesdi B, Juhasz A, Czuriga I, Csiba L: Cerebrovascular reactivity in hypertensive patients: a transcranial Doppler study. J Clin Ultrasound 1997;25: 383-389.

5 Lipsitz LA, Mukai S, Hamner J, Gagnon M, Babikian V: Dynamic regulation of middle cerebral artery blood flow velocity in aging and hypertension. Stroke 2000;31:18971903.

6 Aaslid R, Lindegaard KF, Sorteberg W, Nornes H: Cerebral autoregulation dynamics in humans. Stroke 1989;20:45-52.

7 Anand NK, Tandon L: Prevalence of hypertension in schoolgoing children. Indian Pediatr 1996;33:377-381.

8 Sianiko AR, Gomez-Marin O, Prineas RJ: Prevalence of 'significant' hypertension in junior high school-aged children: the Children and Adolescent Blood Pressure Program. J Pediatr 1989;114:664-669.
9 Elisah M, Papanikolau N, Letzaris G, Dimoliatis J, Siamopoulos KC: Atherosclerotic risk factors in female students of northwestern Greece. J Hum Hypertens 1993;7:533537.

10 Mareczek S, Wyka S, Odrobina S, Cebulak B, Ejma-Multanski J, Fedak M, Sadzik E, Szloch L, Trzaski J, Jakobik K: Arterial blood pressure of high school adolescents in Cracow screening test (in Polish). Przegl Lek 1995; 52:115-118.

11 Nelson MJ, Ragland DR, Syme SL: Longitudinal prediction of adult blood pressure from juvenile blood pressure levels. Am J Epidemiol 1992;136:633-645.

12 Berenson GS, Cresanta JL, Webber LS: High blood pressure in the young. Annu Rev Med 1984;35:535-560.

13 Berenson GS, Srinivasan SR, Hunter SM, Nicklas TA, Freedman DS, Shear CL, Webber LS: Risk factors in early life as predictors of adult heart disease: the Bogalusa Heart Study. Am J Med Sci 1989;298:141-151.

14 Berenson GS, Wattigney WA, Bao W, Nicklas TA, Jiang X, Rush JA: Epidemiology of early primary hypertension and implication for prevention: the Bogalusa Heart Study. J Hum Hypertens 1994;8:303-311.

15 Berenson GS, Srinivasan SR, Bao W, Newman WP, Tracy RE, Wattigney WA: Association between multiple cardiovascular risk factors and atherosclerosis in children and young adults: the Bogalusa Heart Study. N Engl J Med 1998;338:1650-1656.

16 Pieniazek W, Dimitrow PP, Jasinski T: Comparison of the effect of perindopril and acebutolol on cerebral hemodynamics in hypertensive patients. Cardiovasc Drugs Ther 2001;15:63-67.
17 Páll D, Katona É, Fülesdi B, Zrínyi M, Zatik J, Bereczki D, Polgár P, Kakuk GY: Blood pressure distribution in a Hungarian adolescent population: comparison with normal values in the USA. J Hypertens 2003;21:4147.

18 Brouwers PJ, Vriens EM, Musbach M, Wienecke GH, van Huffelen AC: Transcranial pulsed Doppler measurements of blood flow velocity in the middle cerebral artery: reference values at rest and during hyperventilation in healthy children and adolescents in relation to age and sex. Ultrasound Med Biol 1990;16:1-8.

19 Magyar MMT, Valikovics A, Bereczki D, Ficzere A, Czuriga I, Csiba L: Transcranial Doppler monitoring in hypertensive patients during physical exercise. Cerebrovasc Dis 2001;12:186-191.

20 Rodriguez G, Arvigo F, Marenco S, Nobili F, Romano P, Sandini G, Rosadini G: Regional cerebral blood flow in essential hypertension: data evaluation by a mapping system. Stroke 1987;18:13-20.

21 Sugimori H, Ibayashi S, Irie K, Ooboshi H, Nagao T, Fujii K, Sadoshima S, Fujishima M: Cerebral hemodynamics in hypertensive patients compared with normotensive volunteers: a transcranial Doppler study. Stroke 1994;25:1384-1389.

22 Zatik J, Major T, Aranyosi J, Molnár CS, Limburg M, Fülesdi B: Assessment of cerebral hemodynamics during rollover test in healthy and preeclamptic pregnant patients. Br J Obstet Gynecol 2001;8:353-358. 
23 Vriens EM, Kraaier V, Musbach M, Wieneke GH, van Huffeelen AC: Transcranial pulsed Doppler measurements of blood flow velocity in the middle cerebral artery. Reference values at rest and during hyperventilation in healthy volunteers in relation to age and sex. Ultrasound Med Biol 1989;15:1-8.

24 Markwalder T, Grolimund P, Seiler RW, Roth F, Aaslid R: Dependency of blood flow velocity in the middle cerebral artery on endtidal carbon dioxide partial pressure. A transcranaial ultrasound Doppler study. J Cereb Blood Flow Metab 1984;4:368-372.

25 Bradac GB, Simon RS, Heidsieck CH: Angiographically verified transient alteration of the intracranial arteries and veins in dependence of different $\mathrm{CO}_{2}$ tensions. Neuroradiology 1976;10:257-262.

26 Valdueza JM, Balzer JO, Villringer A, Vogl TJ, Kutter R, Einhaupl KM: Changes in blood flow velocity and diameter of the middle cerebral artery during hyperventilation: with MR and transcranial Doppler sonography. Am J Neuroradiol 1997;18:1929-1934.

27 Totaro R, Marini C, Baldassarre M, Carolei A: Cerebrovascular reactivity evaluated by transcranial Doppler: reproducibility of different methods. Cerebrovasc Dis 1999;9: 142-145.
28 Zatik J, Aranyosi J, Molnár Cs, Páll D, Borsos A, Fülesdi B: The effect of hyperventilation on cerebral blood flow velocity in preeclamptic pregnancies. Is there an evidence for an altered cerebral vasoreactivity? J Neuroimaging 2001;11:179-183.

29 Malatino LS, Bellofiore S, Costa MP, Lo Manto G, Finocchiaro F, Di Maria GU: Cerebral blood flow velocity after hyperventilation-induced vasoconstriction in hypertensive patients. Stroke 1992;23:1728-1732.

30 Moller K, Skinhoj P, Knudsen GM, Larsen FS: Effect of short-term hyperventilation on cerebral blood flow autoregulation in patients with acute bacterial meningitis. Stroke 2000;31:1116-1122.

31 Troisi E, Attanasio A, Matteis M, Bragoni M, Caltagironi L, Silvestrini M: Cerebral hemodynamics in young hypertensive subjects and effects of atenolol treatment. J Neurol Sci 1998;15:115-119.

32 Strandgaard S, OB P: Cerebral autoregulation. Stroke 1984;15:413-416.

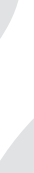

33 Nobili F, Rodriguez G, Marenco S, De Carli F, Gambaro M, Castello C, Postremoli R, Rosadini G: Regional cerebral blood flow in chronic hypertension: a correlative study. Stroke 1993;24:1148-1153.

34 Fujii K, Sadoshima S, Okada Y, Yao H, Kuwabara Y, Ichiya Y, Fujishima M: Cerebral blood flow and metabolism in normotensive and hypertensive patients with transient neurologic deficit. Stroke 1987;21:283-290.

35 Gur AY, Bova I, Bornstein NM: Is impaired vasomotor reactivity a predictive factor of stroke in asymptomatic patients? Stroke 1996;27:2188-2190.

36 Settakis G, Lengyel A, Molnár C, Bereczki D, Csiba L, Fülesdi B: Transcranial Doppler study of the cerebral hemodynamic changes during breath holding and hyperventilation tests. J Neuroimaging 2002;12:252-258.

37 Stoll M, Seidel A, Treib J, Hamann GF: Influence of different techniques of breath holding on the measurement of cerebrovascular reserve in carotid artery disease. Stroke 1996;27:1132-1133.

38 Totaro R, Marini C, Baldassarre M, Carolei A: Cerebrovascular reactivity evaluated by transcranial Doppler: reproducibility of different methods. Cerebrovasc Dis 1999;9: 142-145. 